\title{
Hemodynamic Consequences of Inotropic Support with Digoxin or Amrinone in Lambs with Ventricular Septal Defect
}

\author{
MARK M. BOUCEK, RICHARD CHANG, AND DAVID P. SYNHORST \\ Department of Pediatrics, Division of Cardiologv. University of Utah College of Medicine and The Primary \\ Children's Medical Center, Salt Lake City, Utah 84103
}

\begin{abstract}
Inotropic support with digoxin is commonly used in patients with left ventricular volume overload due to ventricular septal defect (VSD). However, the hemodynamic consequences of inotropic agents with VSD have not been experimentally explored. We studied two inotropic agents, digoxin and amrinone, in chronically instrumented lambs with left ventricular volume overload due to a surgically created VSD. Intravenous digoxin $(40 \mu \mathrm{g} / \mathrm{kg})$ produced serum levels of $3.5 \pm 0.9 \mathrm{ng} / \mathrm{ml}$ (mean $\pm \mathrm{SD}$ ) in seven lambs $60 \mathrm{~min}$ after administration, reduced the heart rate by $16 \%$ (172 to 149 beats/min, $p<0.05)$, increased the stroke volume $16 \%(29.8$ to $34.5 \mathrm{ml} / \mathrm{beat}, p<0.05)$ but did not significantly alter the systemic flow index $\left(\dot{Q}_{s}\right)$, the pulmonary flow index $\left(\dot{Q}_{p}\right)$, or the volume of left to right shunt $\left(\mathrm{Q}_{\mathrm{L}-\mathrm{R}}, 6.74\right.$ to $\left.6.77 \mathrm{liter} / \mathrm{min} / \mathrm{m}^{2}\right)$. The mean left atrial pressure $(\overline{\mathrm{LA}})$ was unchanged $(17.6$ versus $17.1 \mathrm{~mm}$ $\mathrm{Hg}$ ) following digoxin. Chronic digoxin use in four lambs for 4 days $(25 \pm 8 \mu \mathrm{g} / \mathrm{kg} / 8 \mathrm{~h})$ produced trough serum levels of $1.2 \pm 0.2 \mathrm{ng} / \mathrm{ml}$. There was no additional hemodynamic effect compared to acute digoxin, the $\dot{Q}_{\mathrm{p}} / \dot{Q}_{\mathrm{s}}$ ratio was unchanged (3.10 versus 3.08$)$ and evidence of left ventricular volume overload $(\overline{\mathbf{L A}}-14.0$ versus 13.4$)$ was unchanged. Amrinone lowered the systemic resistance index in a dose dependent fashion. The peak reduction of $20 \%$ ( 25.3 to $20.3 \mathrm{U} / \mathrm{m}^{2}, p<0.01$ ) occurred at $20 \mathrm{~min}$ after an intravenous $(3 \mathrm{mg} / \mathrm{kg})$ bolus in seven lambs. The $\dot{Q}_{\mathrm{s}}$ increased from 2.58 to 3.10 liter $/ \mathrm{min} / \mathrm{m}^{2}(p<0.01)$. The $\dot{Q}_{p}$ was unchanged, thus the $\dot{Q}_{\mathrm{p}} / \dot{\mathrm{Q}}_{\mathrm{s}}$ ratio was lowered by $16 \%$ $(p<0.05)$. Amrinone caused a $17 \%$ reduction in $\overline{\mathrm{LA}}(17.9$ to $14.9, p<0.05$ ) and increased the heart rate by $7 \%$. The data indicate that the peripheral vascular effects of amrinone offer a hemodynamic advantage compared to acute digoxin. (Pediatr Res 19: 887-891, 1985)
\end{abstract}

\section{Abbreviations}

VSD, ventricular septal defect

$\dot{Q}_{\mathrm{p}}$, pulmonary flow index

$Q_{s}$, systemic flow index

$\mathbf{R}_{s}$, systemic resistance index

$\mathbf{R}_{\mathrm{pa}}$, pulmonary arteriolar resistance index

$\overline{\mathrm{LA}}$, mean left atrial pressure

Digoxin is generally used in support of the altered hemodynamic state and left ventricular volume overload due to VSD.

Received October 9, 1984; accepted April 8, 1985

Supported by a grant from the Utah Heart Association and USPHS Grants HL2780202 and 2780203 .
However, there are little experimental data on the hemodynamic effects of digoxin in this setting. Support for the use of any inotropic agent with VSD perhaps stems from the observation that myocardial function may be depressed in the presence of hypertrophy (1-3) and in individuals following VSD closure (4, 5). Determination of left ventricular function is impaired by the altered preload and afterload due to VSD. Furthermore, communication between the right and left ventricle complicates measuring isolated parameters of left ventricular function. Since the inotropic state of the myocardium is a major determinant of hemodynamic variables, such as the cardiac output or stroke volume at a given filling pressure, we sought to evaluate the effects of inotropic support indirectly by measuring the hemodynamic changes in a chronically instrumented model of VSD.

The absence of controlled clinical studies demonstrating digoxin efficacy with VSD and reports of therapeutic failure of digoxin in some infants $(6,7)$ has caused the use of digitalis preparations with left to right shunts to be questioned (8). A recent clinical study of VSD found that $50 \%$ showed improvement following digoxin (9). Failure of medical management with digoxin and diuretics has led to early surgical correction despite the observation that the majority of ventricular septal defects will either diminish in size or close spontaneously with growth of the child $(10,11)$.

Vasodilating agents have been shown to be helpful in patients with volume overload of the left ventricle due to mitral (12) or aortic (13) insufficiency or VSD (14). Experimental studies have also shown hemodynamic improvement with VSD $(15,16)$ or aortocaval fistula (17) following vasodilators. With an aortocaval fistula and left ventricular volume overload nitroprusside was effective at decreasing evidence of volume overload while digoxin was not (17).

Amrinone is a new inotropic agent which also has direct peripheral vasodilating properties $(18,19)$. Digoxin either has little effect or may actually increase arterial and venous tone (20). We evaluated the hemodynamic effects of inotropic support in a chronic, nonsedated, instrumented lamb model with VSD and left ventricular volume overload. Since vasodilators are useful with VSD (14-16) we studied the hemodynamic changes following acute and chronic digoxin and those following amrinone.

\section{METHODS}

The details for creating the VSD in lambs and subsequent instrumentation have been previously published (16). Basically, lambs (approximately 2 wk old) were anesthetized with ketamine and a Teflon grommet was placed across the interventricular septum through a right atriotomy. The defects were $8 \mathrm{~mm}$ in internal diameter and resulted in indexed pulmonary to systemic blood flow ratios $\left(\dot{Q}_{\mathrm{p}} / \dot{\mathrm{Q}}_{\mathrm{s}}\right)$ greater than 3 to 1 . After a 1-wk 
recovery period, the lambs were instrumented with aortic and pulmonary artery electromagnetic flow probes (Biotronix Inc.). Indwelling catheters were inserted into the left atrium, right atrium, pulmonary artery, and aorta. The animals were again allowed to recover for at least $1 \mathrm{wk}$ prior to data collection. All the lambs were spontaneously active, feeding, and had normal arterial blood gasses after the recovery period. The total group of 11 lambs used to study digoxin was not the exact same group of nine lambs used for amrinone studies since there was occasionally loss of catheters or flow probe malfunction between studies.

\section{DRUG ADMINISTRATION}

Only one drug was administered on a given day and, following digoxin use, at east $72 \mathrm{~h}$ elapsed prior to any subsequent drug trials which allowed for clearance of digoxin. The lambs were studied while standing quietly in a supporting cradle after a 30 min stabilization period. Amrinone was dissolved in a lactic acidascorbic acid solution and was diluted and filtered through a $0.45 \mu$ Millipore filter prior to use. In three lambs the dose response to amrinone was determined. The dose causing maximal systemic vasodilation $(3 \mathrm{mg} / \mathrm{kg}$ ) was then given to each lamb with data recorded at 10 -min intervals for a total of $60 \mathrm{~min}$. Sham infusions with the amrinone vehicle were also performed. Complete hemodynamic measurements were available from seven lambs and flow variables were available in two additional animals with amrinone.

Digoxin was obtained from the hospital pharmacy as the injectable preparation. Each lamb was given a dose of $40 \mu \mathrm{g} / \mathrm{kg}$ as a slow intravenous bolus. The electrocardiogram was continuously monitored. Data were recorded at 15 -min intervals over a total period of $120 \mathrm{~min}$. Complete hemodynamic data were available in seven lambs with digoxin. Subsequently, digoxin was continued for 4 days with daily observations in four additional lambs. Following the loading dose digoxin was administered intravenously every $8 \mathrm{~h}$ to maintain the trough serum concentration greater than $1 \mathrm{ng} / \mathrm{ml}$.

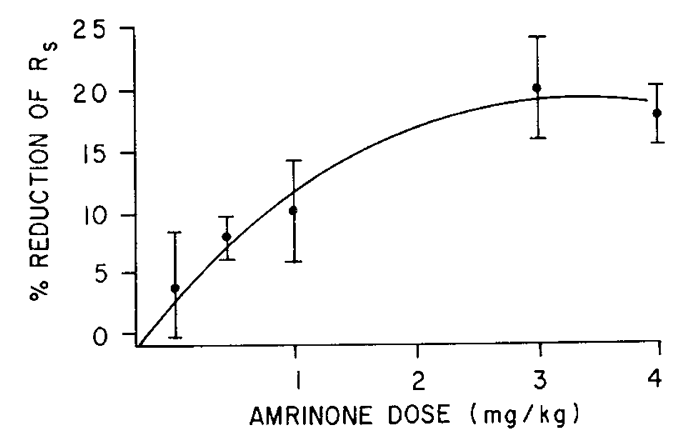

Fig. 1. Dose response curve for the effect of amrinone on the systemic resistance expessed as percentage reduction from control. Brackets indicate the $\mathrm{SD}(n=3)$.

\section{DATA REDUCTION}

Flow and resistance data were indexed to the body surface area (16). Data following drug administration were compared to control data obtained immediately prior to drug use and after the lamb had stabilized. Data for each point included the $\dot{Q}_{s}$, the $\dot{Q}_{p}$, phasic and mean aortic, pulmonary artery and left atrial pressures. The heart rate was recorded continuously. Resistance data were calculated by dividing the appropriate mean arterial pressure by the flow (16) and are expressed without units.

Digoxin levels were performed in the clinical lab using a radioimmunoassay (21).

\section{STATISTICAL METHODS}

The data were evaluated statistically using analysis of variance and Dunnet's method for comparing sequential posttreatment values with the control (22). The Student's $t$ test with the Bonferroni adjustment of critical values was used for analyzing the single point data obtained at the time of peak drug effect.

\section{RESULTS}

Amrinone. Amrinone produced a dose $(0.1$ to $4.0 \mathrm{mg} / \mathrm{kg})$ dependent decrease in $R_{s}$ with maximum effect occurring at approximately $3 \mathrm{mg} / \mathrm{kg}$ (Fig. 1). Doses up to $1 \mathrm{mg} / \mathrm{kg}$ did not change the $R_{p a}$. A dose greater than $1 \mathrm{mg} / \mathrm{kg}$ reduced $R_{p a}$ slightly although the change was not significant.

Amrinone $(3 \mathrm{mg} / \mathrm{kg}$ ) was administered to nine lambs by bolus injection and in seven complete hemodynamic data were available (Table 1). Within 10 min there was a $16 \%$ reduction $(25.3$ to $20.8 \mathrm{U})$ in the $\mathrm{R}_{\mathrm{s}}$. The $\dot{\mathrm{Q}}_{\mathrm{s}}$ increased $20 \%(2.58$ to 3.08 liter/ $\mathrm{min} / \mathrm{m}^{2}$ ) without a significant change in the $\mathrm{Q}_{\mathrm{p}}$ (Fig. 1). Thus, the $\dot{\mathrm{Q}}_{\mathrm{p}} / \dot{\mathrm{Q}}_{\mathrm{s}}$ ratio decreased $17 \%(3.65$ to $3.04, p<0.05)$. Peak effect occurred at $20 \mathrm{~min}$ when the $\mathrm{R}_{\mathrm{s}}$ was decreased by $20 \%$. The $R_{p a}$ was unchanged $\left(1.41\right.$ to $\left.1.46 \mathrm{U} / \mathrm{m}^{2}\right)$ and the $R_{p a} / R_{s}$ ratio (Table 1$)$ increased by $27 \%(0.055$ to $0.07, p<0.05)$. The $\dot{Q}_{p} / \dot{Q}_{s}$ ratio was lowered by $16 \%$. The hemodynamic changes persisted for approximately $30 \mathrm{~min}$ and slowly returned toward control values by $60 \mathrm{~min}$ (Fig. 2). The $\overline{\mathrm{LA}}$ also returned toward control values by $60 \mathrm{~min}$. The stroke volume was unchanged (Table 1). With sham drug administration the amrinone vehicle alone did not significantly alter any observed parameter or the arterial blood gas.

Digoxin. Following an intravenous bolus of digoxin $(40 \mu \mathrm{g} /$ $\mathrm{kg}$ ) in seven lambs, a serum level of $3.5 \pm 0.9 \mathrm{ng} / \mathrm{ml}$ (mean \pm SD) was obtained at $60 \mathrm{~min}$. Digoxin effect (Table 1) was demonstrated by a reduction in heart rate $(172$ to $149, p<0.05)$ and an increase in SV from 30 to $35 \mathrm{ml} /$ beat $(p<0.05)$. However, none of the flow parameters $\left(\dot{Q}_{p}, \dot{Q}_{s}, Q_{p} / \dot{Q}_{s}\right)$ were significantly altered (Fig. 3). The left to right shunt volume was unchanged $\left(6.73\right.$ to $\left.6.77 \mathrm{liter} / \mathrm{min} / \mathrm{m}^{2}\right)$. Digoxin did not significantly affect aortic or pulmonary artery pressures or resistances. Furthermore, the left atrial pressure was unchanged (17.7 versus

Table 1. Peak effect of amrinone and digoxin [values are mean $\pm S E(n=7)$ ]

\begin{tabular}{|c|c|c|c|c|c|c|}
\hline & \multicolumn{3}{|c|}{ Amrinone } & \multicolumn{3}{|c|}{ Digoxin } \\
\hline & Control & $20^{\prime}$ & $\%$ Change & Control & $60^{\prime}$ & $\%$ Change \\
\hline$\dot{\mathrm{Q}}_{\mathrm{s}}\left(\right.$ liter $\left.\cdot \min / \mathrm{m}^{2}\right)$ & $2.58 \pm 0.17$ & $3.10 \pm 0.16$ & $+20^{*}$ & $2.92 \pm 0.28$ & $2.73 \pm 0.26$ & -7 \\
\hline$\dot{\mathrm{Q}}_{\mathrm{p}}\left(\mathrm{liter} / \mathrm{min} / \mathrm{m}^{2}\right)$ & $9.41 \pm 1.13$ & $9.57 \pm 1.10$ & +2 & $9.65 \pm 0.98$ & $9.48 \pm 1.0$ & -2 \\
\hline$\dot{Q}_{\mathrm{p}} / \dot{Q}_{\mathrm{s}}$ & $3.65 \pm 0.20$ & $3.08 \pm 0.20$ & $-16^{*}$ & $3.34 \pm 0.22$ & $3.46 \pm 0.18$ & +4 \\
\hline $\mathrm{R}_{\mathrm{s}}(\mathrm{U})$ & $25.3 \pm 1.7$ & $20.3 \pm 1.0$ & $-20^{*}$ & $23.5 \pm 2.3$ & $24.5 \pm 2.1$ & +4 \\
\hline$\underline{\mathrm{R}_{\mathrm{pa}} / \mathrm{R}_{\mathrm{s}}}$ & $0.055 \pm 0.008$ & $0.069 \pm 0.005$ & $+25^{*}$ & $0.072 \pm 0.014$ & $0.064 \pm 0.01$ & -11 \\
\hline$\overline{\mathrm{LA}}(\mathrm{mm} \mathrm{Hg})$ & $17.9 \pm 3.5$ & $14.9 \pm 2.8$ & $-17^{*}$ & $17.6 \pm 1.6$ & $17.1 \pm 1.9$ & -3 \\
\hline$\overline{\mathrm{Ao}}(\mathrm{mm} \mathrm{Hg})^{\dagger}$ & $63.7 \pm 1.5$ & $62.2 \pm 1.4$ & -2 & $64.6 \pm 0.8$ & $63.8 \pm 1.9$ & -1 \\
\hline Heart rate (beat/min) & $151 \pm 10.0$ & $162 \pm 13.0$ & +7 & $172 \pm 8.0$ & $149 \pm 10.0$ & $-14^{a}$ \\
\hline Stroke volume (ml/beat) & $32.7 \pm 2.7$ & $31.7 \pm 2.5$ & -3 & $29.8 \pm 2.2$ & $34.5 \pm 3.3$ & $+16^{a}$ \\
\hline
\end{tabular}

${ }^{*} p<0.05$ compared to control (paired $t$ test).

$\dagger$ Mean aortic pressure. 


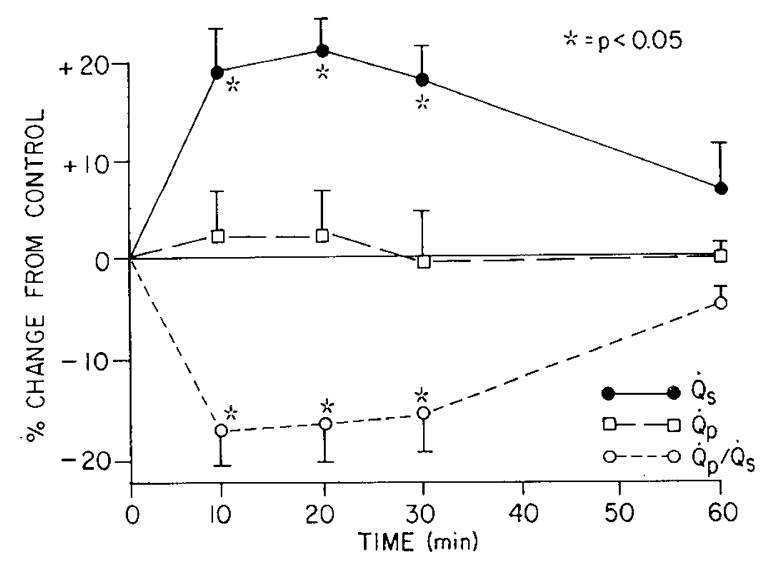

Fig. 2. The effects of amrinone with respect to time in terms of the percentage change from control for the indicated flow parameter. The asterisks indicate a significant change from control at the $p<0.05$ level by analysis of variance and Dunnet's test $(n=9)$.

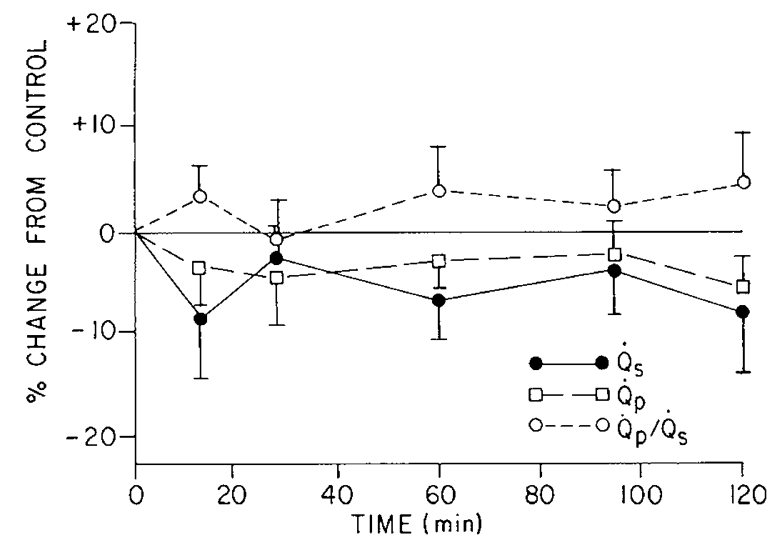

Fig. 3. The effects of digoxin with respect to time in terms of the percentage change from control for the indicated flow parameter. None of the changes was significant by analysis of variance. Brackets indicate the standard deviation $(n=7)$.

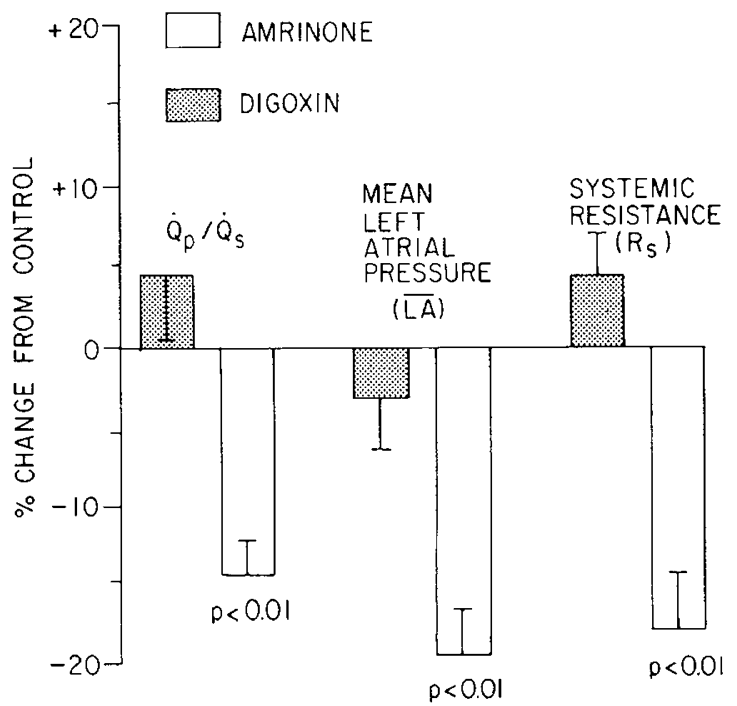

Fig. 4. Bar graph comparison between the effects of digoxin at 60 min (hatched) and amrinone at $30 \mathrm{~min}$ (open) on the indicated hemodynamic parameter. Brackets indicate the SD.

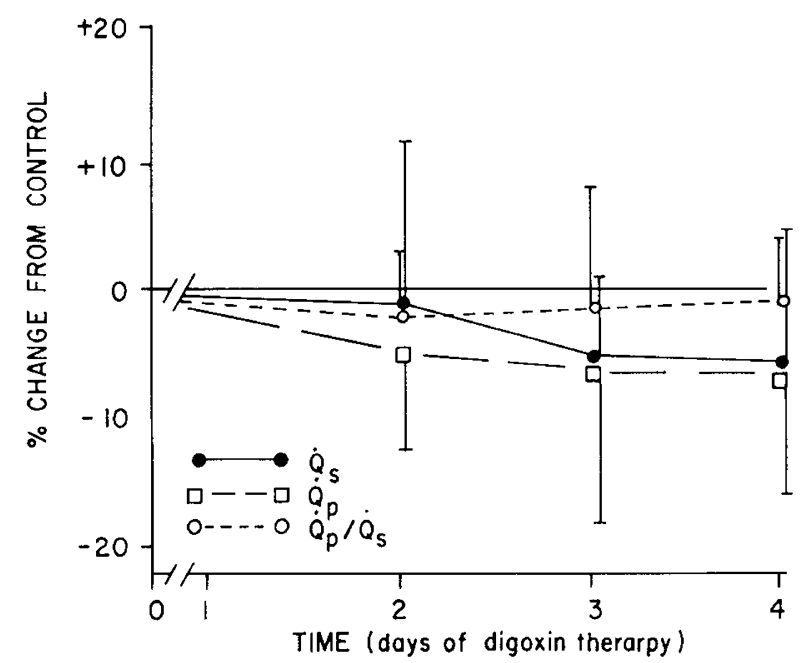

Fig. 5. The effects of chronically administered digoxin on the indicated flow parameter. Values are the mean percentage change from control and SD. None of the points was significantly different from control by analysis of variance $(n=4)$.

Table 2. Stability of the model versus digoxin effect with time* (mean $\pm S E$

\begin{tabular}{llcccc}
\hline & & $\begin{array}{c}\text { Sham } \\
(n=5)\end{array}$ & $\begin{array}{c}\% \\
\text { Change }\end{array}$ & $\begin{array}{c}\text { Digoxin } \\
(n=4)\end{array}$ & $\begin{array}{c}\% \\
\text { Change }\end{array}$ \\
\hline \multirow{2}{*}{$\mathrm{Q}_{\mathrm{p}} / \mathrm{Q}_{\mathrm{s}}$} & Baseline & $3.4 \pm 0.4$ & & $3.10 \pm 0.5$ & -1 \\
$\overline{\mathrm{LA}}$ & Day 4 & $3.6 \pm 0.6$ & +5 & $3.08 \pm 0.6$ & -1 \\
& Baseline & $18.8 \pm 4.4$ & & $14.0 \pm 2.9$ & -4 \\
$\mathrm{R}_{\mathrm{s}}$ & Day 4 & $18.9 \pm 1.9$ & +1 & $13.4 \pm 2.5$ & \\
& Baseline & $24.4 \pm 4.9$ & & $30.3 \pm 4.4$ & +1 \\
$\mathrm{HR}$ & Day 4 & $23.9 \pm 6.8$ & -2 & $30.4 \pm 3.0$ & \\
Stroke vol- & Baseline & $166 \pm 18$ & & $172 \pm 29$ & $-16 \dagger$ \\
\multicolumn{1}{c}{ ume } & Day 4 & $164 \pm 20$ & -1 & $144 \pm 30$ & \\
\hline
\end{tabular}

* Serial observations in 5 lambs without pharmacologic intervention versus the observed effects of chronic digoxin in four different lambs.

$\dagger p<0.05$ (day 4 versus baseline).

$17.1 \mathrm{~mm} \mathrm{Hg}$, Fig. 4). The pattern of response persisted during the 2-h observation period (Fig. 3).

Digoxin was then administered chronically for 4 days to four instrumented lambs. Digoxin was given intravenously every $8 \mathrm{~h}$ to maintain a trough serum digoxin concentration greater than $1 \mathrm{ng} / \mathrm{ml}$. The mean dose was $25 \pm 8 \mu \mathrm{g} / \mathrm{kg} / 8 \mathrm{~h}$, and the mean trough serum digoxin concentration on day 4 was $1.2 \pm 0.2 \mathrm{ng} /$ $\mathrm{ml}$. Using a single compartment model the half-life of digoxin with chronic therapy was approximately $15 \mathrm{~h}$ with an elimination constant of $0.0458 / \mathrm{h}$. The pattern of response for chronic digoxin was identical to acute digoxin (Fig. 5). There was no significant effect on any of the flow, pressure, or resistance parameters. There was a significant reduction in heart rate $(173 \pm 29$ to 144 $\pm 30, p<0.05)$ and the stroke volume increased $(28.3 \pm 7.3$ to $32.1 \pm 9.2$ ). In five control instrumented lambs there was no significant change in any hemodynamic variable over a 4-day observation period (Table 2).

\section{DISCUSSION}

The role of depressed myocardial function with left ventricular volume overload due to left to right shunts such as VSD remains controversial (8). Inotropic support with digoxin continues to be part of the initial medical management for patients with VSD. The most severely affected infants often fail to respond satisfactorily and require surgery in infancy. Optimizing medical management may allow the child to grow to a size which lessens the 
surgical risk (23) or may allow for spontaneous closure of the defect in some $(10,11)$.

The experimental evaluation of digoxin in the presence of left ventricular volume overload from VSD has not been previously reported. To explore the hemodynamic effects of digoxin we studied nonsedated, unanesthetized lambs with a surgically created VSD. Since the effects of right ventricular communication on estimates of left ventricular function are unknown we indirectly assessed the response to pharmacologic inotropic support by measuring hemodynamic variables. If changes in the inotropic state were critical to the pathophysiologic hemodynamic state with VSD then alterations in the inotropic state should be reflected in hemodynamic measurements.

Digoxin did not significantly alter in seven acutely and four chronically studied lambs any of the abnormal hemodynamic parameters associated with VSD found in this model. Serum digoxin levels were in the therapeutic range and digoxin effect was demonstrated by slowing of the heart rate. In addition, the increase in stroke volume, despite an unchanged $\overline{\mathrm{LA}}$ (estimate of preload), and an unchanged $R_{s}$ or $R_{p a}$ (estimates of afterload) would support an inotropic effect of digoxin. Despite this evidence of digoxin effect the various flow, pressure, or resistance hemodynamic variables were unchanged. Since digoxin does not have a selective vascular action (20) it is not unexpected that the $\dot{\mathrm{Q}}_{\mathrm{p}} / \dot{\mathrm{Q}}_{\mathrm{s}}$ ratio was unchanged. However, if depressed myocardial function was important in the development of left ventricular volume overload one might anticipate changes in the loading characteristics of the left ventricle following digoxin for the same left to right shunt. We did not observe a significant change in mean left atrial pressure with digoxin. The fact that digoxin did not decrease left atrial hypertension is important because this hemodynamic variable may most closely correlate to clinical symptoms of pulmonary congestion and may be related to the development of pulmonary hypertension (6).

The clinical impression of digoxin effectiveness in some patients may represent a subset in whom myocardial dysfunction contributes to symptoms (9) or may relate to other effects of digoxin such as on the central nervous system (24) or kidney (25). In fact, in children with VSD the clinical assessment of digoxin effect did not necessarily correlate with echocardiographic estimates of inotropic response (9). The ability to increase cardiac output by increasing heart rate represents a form of cardiovascular reserve. If the heart rate is decreased and cardiac output maintained following digoxin it may be that a portion of heart rate reserve has been regained. The reduction in heart rate noted in this study was seen in both acute and chronic digoxin. The increased heart rate reserve may contribute to the clinical impression of digoxin effect.

Fetal lambs have been shown to be less sensitive to both the toxic and inotropic effects of digoxin compared to ewes, despite similar tissue-plasma ratios (26). A possible explanation for the lower inotropic response may be that the newborn lamb myocardium functions closer to the maximum inotropic state than the adult (27) and, thus, is less sensitive in terms of percentage change to inotropic stimulation. The data from this study were collected on lambs approximately 4 to $6 \mathrm{wk}$ old which would more closely approximate the adult hemodynamic state (28). Although the acute serum digoxin levels in this study do not represent steady state kinetics with respect to tissue distribution, there was clearly a significant change in heart rate and stroke volume (Fig. 4) by $60 \mathrm{~min}$. Furthermore, chronic administration of digoxin, which would allow for tissue equilibration, produced essentially the same hemodynamic effects as acute administration (Fig. 5, Table 2). No significant arrhythmias were observed in this study. We have previously shown that this model is stable for acute observation (16). Data presented here indicate that the model is also stable for chronic observation (Table 2).

The importance of the $R_{p a} / R_{s}$ ratio in regulating the abnormal hemodynamics associated with VSD has been reported (29). This information has led to the experimental demonstration of a beneficial effect of selective systemic vasodilatation on the left to right shunt found with VSD (14-16). Amrinone is an inotropic agent with direct systemic vasodilating properties. We studied amrinone and digoxin because of this important difference.

Amrinone was found to favorably alter the abnormal hemodynamics in this model (Fig. 2). The reduction in $R_{s}$ was accompanied by a reduction in $\mathrm{Q}_{\mathrm{p}} / \mathrm{Q}_{\mathrm{s}}$ and the $\overline{\mathrm{LA}}$ was lowered $17 \%(p$ $<0.01$, Fig. 4). As the $\dot{Q}_{p}$ was not significantly decreased, the reduction in LA may be due to the decreased afterload $\left(\mathrm{R}_{\mathrm{s}}\right)$ on the left ventricle and/or an inotropic effect of amrinone. The reduction in $\bar{L} \bar{A}$ may be due to the decreased afterload $\left(R_{s}\right)$ on the left ventricle and/or an inotropic effect of amrinone. The stroke volume was unchanged with amrinone but both the preload $(\overline{\mathrm{LA}})$ and afterload $\left(\mathrm{R}_{\mathrm{s}}\right)$ were altered and, thus, lack of change in $S V$ cannot be directly interpreted as lack of change in the inotropic state. The reduction in $\overline{\mathrm{LA}}$ and $\dot{\mathrm{Q}}_{\mathrm{p}} / \dot{\mathrm{Q}}_{\mathrm{s}}$ and the increased $\dot{Q}_{s}$ would be beneficial alterations and most likely reflect the change in $R_{s}$. An inotropic effect alone would not explain the redistribution of flow observed with amrinone, but may contribute to the reduction in $\overline{\mathrm{LA}}$. Amrinone caused a dosedependent reduction in $\mathrm{R}_{\mathrm{s}}$ and $\dot{\mathrm{Q}}_{\mathrm{p}} / \dot{\mathrm{Q}}_{\mathrm{s}}$. However, the maximum change in $\dot{Q}_{p} / \dot{Q}_{s}$ occurred at a lower dose than the maximum change in $R_{s}$ since with increasing amrinone dose a pulmonary vasodilating response was observed, as previously reported (30). There is also an age-dependent response to amrinone. Isolated canine neonatal myocardium is relatively insensitive to amrinone, but the response matures rapidly with age (31). In six lambs of a similar age without VSD, we found that amrinone (3 $\mathrm{mg} / \mathrm{kg}$ ) caused an $18 \%$ increase in $\mathrm{LV} \mathrm{dP} / \mathrm{dt}_{40}$ (2631 versus 3109 $\mathrm{mm} \mathrm{Hg} / \mathrm{s}) 30 \mathrm{~min}$ after bolus administration indicating that normal lambs of this age are capable of demonstrating an inotropic response to amrinone.

The data show that acute or chronic inotropic support with digoxin at therapeutic serum levels did not significantly change any hemodynamic parameter in a total of 11 lambs with chronic left ventricular volume overload due to VSD. These data may indicate that a generalized depression in myocardial function does not play a major role in determining the abnormal hemodynamics seen with VSD. There was a reduction in heart rate despite no significant change in systemic flow, thus, digoxin apparently did cause some recovery of heart rate reserve. The change in heart rate with digoxin may be due to its inotropic properties or perhaps via its effects on the autonomic nervous system. Amrinone decreased several important hemodynamic variables found with VSD and a large left to right shunt including systemic resistance, the $\dot{\mathrm{Q}}_{\mathrm{p}} / \dot{\mathrm{Q}}_{\mathrm{s}}$ ratio, and left atrial hypertension. Despite the reduction in mean left atrial pressure, amrinone increased systemic blood flow without significantly effecting the heart rate. These changes would be hemodynamically beneficial.

Acknowledgments. Amrinone was a generous gift from $\mathrm{D}$. Davalos, M.D. The authors sincerely appreciate the assistance of Amanda Sue Butterfield in manuscript preparation and $\mathrm{W}$. Manford Gooch, M.D. in pharmacokinetic calculations.

\section{REFERENCES}

1. Spann JR, Buccino RA, Sonnenblick EH, Braunwald E 1967 Contractile state of cardiac muscle obtained from cats with experimentally produced ventricular hypertrophy and heart failure. Circ Res 21:341-354

2. Katz AM 1975 Congestive heart failure. N Engl J Med 293:1184-1191

3. Wikman-Coffelt J, Pharmley WW, Mason DT 1979 The cardiac hypertrophy process. Circ Res 45:697-707

4. Jarmakani JM, Graham TP, Canent RV 1972 Left ventricular contractile state in children with successfully corrected ventricular septal defect. Circulation 45(suppl 1):I-102-I-110

5. Jablonski G, Hilton JD, Liu PP, Morch JE, Druck MN, Bar-Shlomo B, McLaughlin PR 1983 Rest and exercise ventricular function in adults with congenital ventricular septal defects. Am J Cardiol 51:293-298

6. Hoffman JIE, Rudolph AM 1965 The natural history of ventricular septal defects in infancy. Am J Cardiol 16:634-653

7. Talner NS 1971 Congestive heart failure in the infant. Pediatr Clin North Am 18:1011-1029

8. White RD, Lietman PS 1978 Commentary: a reappraisal of digitalis for infants 
with left-to-right shunts and "heart failure." J Pediatr 92:867-870

9. Berman WJR, Yabek SM. Dillon X. Niland C. Corlew S. Christensen D 1983 Effects of digoxin in infants with a congested circulatory state due to a ventricular scptal defect. N Engl J Med 308:363-366

10. Collins G. Calder L. Rose V, Kidd L. Keith J 1972 Ventricular septal defect: clinical and hemodynamic changes in the first five years of life. Am Heart $\mathrm{J}$ 81:695-705

11. Mesko ZG. Jones JE. Nadas AS 1973 Diminution and closure of large ventricular septal defects after pulmonary artery banding. Circulation 48:847-855

12. Chatterjee K. Pharmley WW. Swan HJC, Bernam G, Forrester J, Marcus H 1973 Beneficial effects of vasodilator agents in severe mitral regurgitation due to dysfunction of subvalvular apparatus. Circulation 48.684-690

13. Greenberg BH, Demots H. Murphy E, Rahimtoola S 1980 Beneficial effects of hydralazine on rest and exercise hemodynamics in patients with chronic severe aortic insufficiency. Circulation 62:49-55

14. Beekman RH. Rochini AP. Rosenthal A 1982 Hemodynamic effects of hydralazine in infants with a large ventricular septal defect. Circulation 65:523528

15. Synhorst DP. Lauer RM. Doty DB. Brody MJ 1976 Hemodynamic effects of vasodilator agents in dogs with experimental ventricular septal defect. Circulation 54:472-477

16. Boucek MM, Chang R. Svnhorst DP 1984 Vasodilators and ventricular septal defect: comparison of prazosin, minoxidil and hydralazine in a chronic lamb model. Pediatr Res 18:859-864

17. O'Rourke RA. Badke FR. Frost D 1982 Comparative hemodynamic effects of digoxin vs nitroprusside in conscious dogs with aortocaval fistula-induced chronic left ventricular volume overload and normal systolic performance. Am Heart J 103:489 497

18. Alousi AA. Farah AE, Lesher GY. Opalka CJ 1979 Cardiotonic activity of amrinone-WIN 40680 [5-amino-3.4'-bipyridin-6(IH)-ONE]. Circ Res
$45: 666-677$

19. Benotti JR, Grossman W, Braunwald E, Davolos DD, Alousi AA 1978 Hemodynamic assessment of amrinone. N Engl J Med 299:1373-1377

20. Mikkelson E, Andersson K-E, Lederballe Pederson O 1979 Effects of digoxin on isolated human peripheral arteries and veins. Acta Pharmacol Toxicol 45:249-256

21. Jolley ME 1981 Fluorescence polarization immunoassay for determination of therapeutic drug levels in human plasma. J Anal Toxicol 5:236-240

22. Dunnett LW 1964 New tables for multiple comparisons with a control. Biometrics 20:482-491

23. Fisher DR, Faulkner SL. Sell CG, Graham TP, Bender HW 1978 Operative closure of isolated defects of the ventricular septum: planned delay. Arin Thorac Surg 26:351-356

24. Gillis RA, Quest 1980 The role of the nervous system in the cardiovascular effects of digitalis. Pharmacol Rev 31:19-84

25. Blaine EH, Zimmerman MB 1978 Renal function and renin secretion after administration of oubain and oubain plus furosemide in conscious sheep. Circ Res 43:36-43

26. Berman W, Rauenscroft PJ, Sheiner LB, Heymann MA, Melon KL, Rudolph AM 1977 Differential effects of digoxin at comparable concentrations in tissues of fetal and adult sheep. Circ Res 41:635-642

27. Berman W. Musselman J 1979 Myocardial performance in the newborn lamb. Am J Physiol 237:H66-70

28. Klopfenstein HS, Rudolph AM 1978 Postnatal changes in the circulation and responses to volume loading in sheep. Circ Res 42:839

29. Rudolph AM 1965 The effects of postnatal circulatory adjustments in congenital heart disease. Pediatrics 36:763-772

30. Mammel MC, Einzig S, Kulik TJ. Thompson TR, Lock JE 1983 Pulmonary vascular effects of amrinone in conscious lambs. Pediatr Res 17:720-724

31. Binah O, Rosen MR 1983 Developmental changes in the cardiac effects of amrinone in the dog. Circ Res 52:747-752 